\title{
Restauración y ampliación ex Casa Gandarillas
}

\section{Memoria}

Localizado en un extenso terreno al suroriente de la intersección de las Avenidas Colón y Padre Hurtado, el conjunto es el testimonio tangible de una de las más interesantes casas patronales de la zona central. Su origen rural se manifiesta al visitante: una explanada de acceso derivada del camino; la Llavería (dos pabellones de adobe cubiertos de teja otrora destinados a animales); la Casona, residencia de la familia; la zona de servicio. Y el conjunto todo, enfrentando un exuberante parque con árboles centenarios y especies nativas.

El proyecto reconoce sus atributos esenciales. Los formales y los espaciales. Preserva las materialidades que le otorgan identidad $y$, sin perder de vista el principio de la compatibilidad física, incorpora tecnología contemporánea. El nuevo destino exigió márgenes de seguridad sólo posibles con los recursos del hormigón y el acero, cuando imprescindibles.

La puesta en valor trajo consigo funciones en sintonía con el espíritu del conjunto: su carácter rural, la longitud de los corredores y la amplitud de los espacios abiertos acoge sin resistencias el Museo de la Chilenidad y las oficinas de la Federación de Criadores de Caballos Chilenos.

El sector antiguo de la Llavería, que conservó su estructura e ingenua rusticidad, fue reforzado con elementos complementarios: vigas metálicas y machones de hormigón armado. El sector nuevo, manteniendo relaciones métricas con lo antiguo, evidencia su actualidad.

La antigua casa de la familia fue objeto de acciones menores que buscaron rejuvenecerla sin alterar sus características estructurales ni formales.
Parte del diseño son los espacios abiertos: Explanada, Plaza de la Llavería, Patio de los Naranjos y Estacionamientos. El proyecto se materializa en un lugar de encuentro social y en un verdadero albergue de las más genuinas tradiciones chilenas.

\section{Ficha técnica}

Autores:

InReAr - Instituto de Restauración

Arquitectónica, Facultad de Arquitectura y Urbanismo, Universidad de Chile

Jefe de proyecto:

Arqto. Antonio Sahady V.

\section{Coordinador:}

Arqto. Felipe Gallardo G.

Jefe taller:

Arqto. Daniel Espinoza N.

Colaboradores:

Arqto. Luis Albornoz M.

Arqta. Dana Cerda T.

Arqta. Cecilia Guzmán S.

Arqto. Matías Mella Z.

\section{Asesores técnicos}

Cálculo y diseño estructural: Arqto. Juan Martínez M. Ing. José Cortés Collado

Instalaciones eléctricas: Óscar Vargas P.

Instalaciones sanitarias: Vidal y Bahamondes Ltda.
Construcción:

Empresa Constructora ASCOM Limitada

Inspección de obra:

Arqto. José Vergara

Arqta. Verónica Siré

Registro:

Daniel Espinoza

Felipe Gallardo

Antonio Sahady

Flor Recabarren

Localización:

Avenida Padre Hurtado No 1.155, comuna de Las Condes, Santiago, RM.

Superficie del terreno:

Terreno Parque Casa Gandarillas: 6,3 hectáreas $\left(63.000 \mathrm{~m}^{2}\right)$, propiedad de la I. Municipalidad de Las Condes

Superficie del proyecto: $2.151 \mathrm{~m}^{2}$

Primera Etapa $2.000 \mathrm{~m}^{2}\left(2.151,2 \mathrm{~m}^{2}\right.$, albañilería de ladrillo y adobe, refuerzos de hormigón armado)

Segunda Etapa $1.700 \mathrm{~m}^{2}$; Áreas exteriores: $3.000 \mathrm{~m}^{2}$

Año del proyecto: 2006

Año de construcción: 2007-2008

Materiales predominantes: Adobe, hormigón armado y madera.

Costo $\mathrm{m}^{2}$ : $\$ 255.695 \mathrm{~m}^{2}$ construido (aprox. 13 UF/ $\left.\mathrm{m}^{2}\right)$ 


\section{$6 \log 9$ \\ ong}

(6)

Nong ing

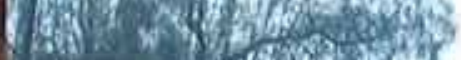

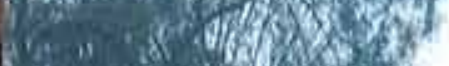

(3) 50 (4)

(3i 4 iो

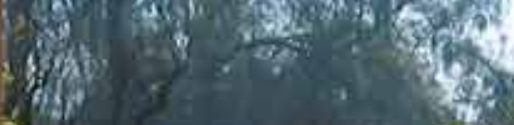

is

$k=-4)=$

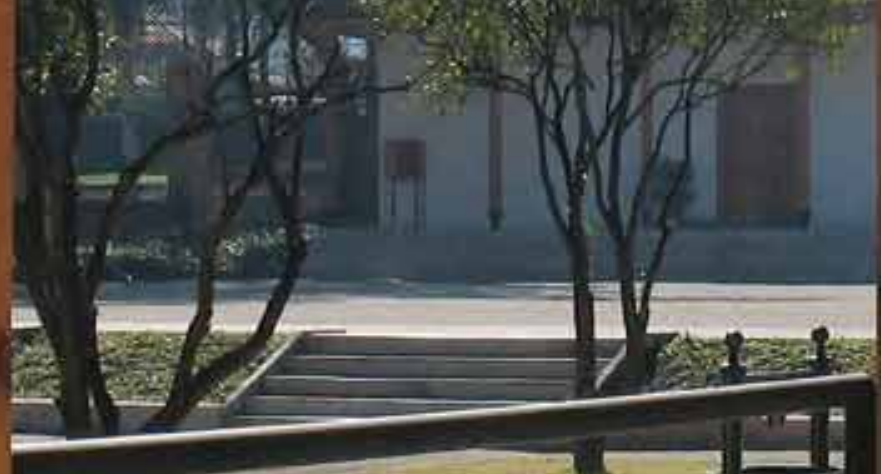

$30 \mathrm{cos}=\mathrm{m}$

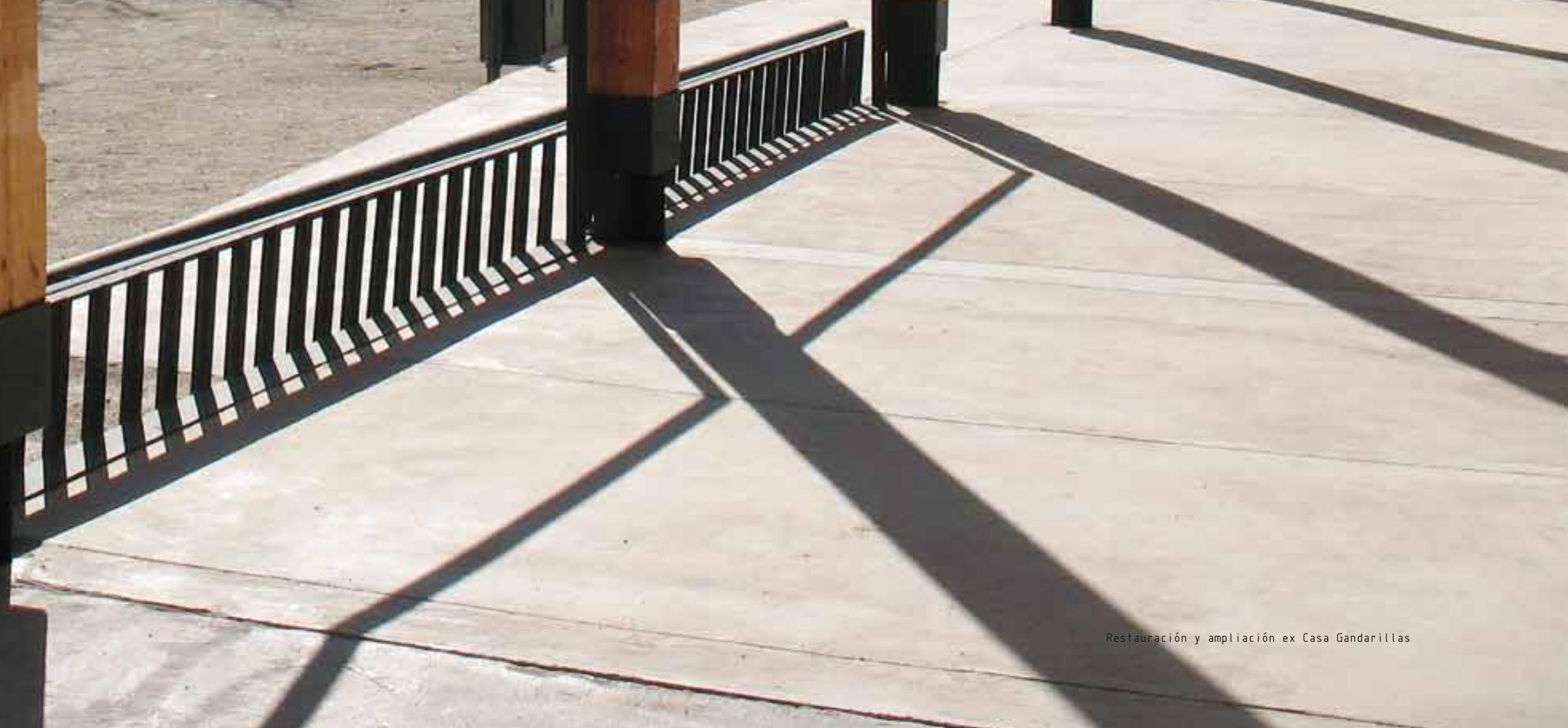




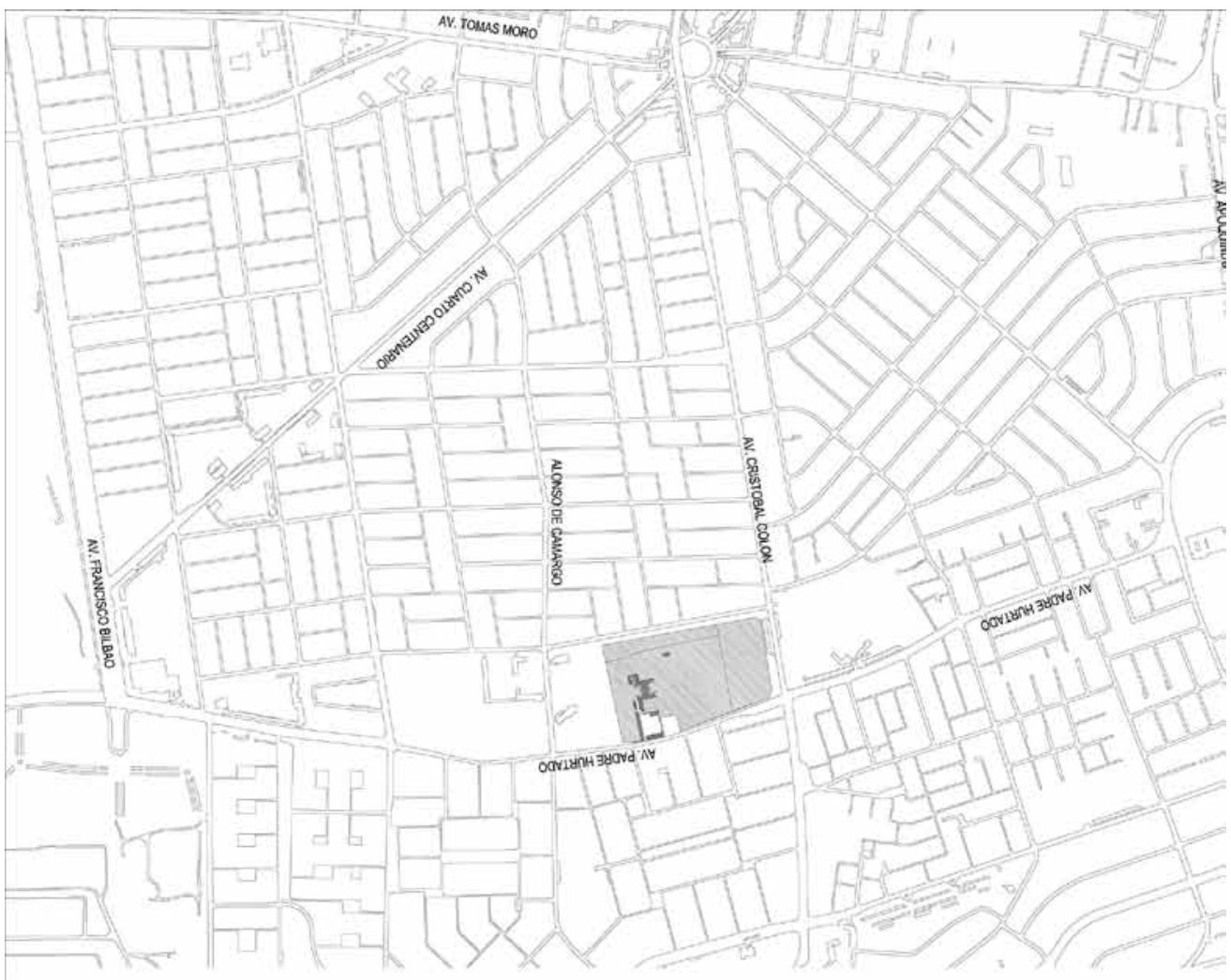

Ubicación

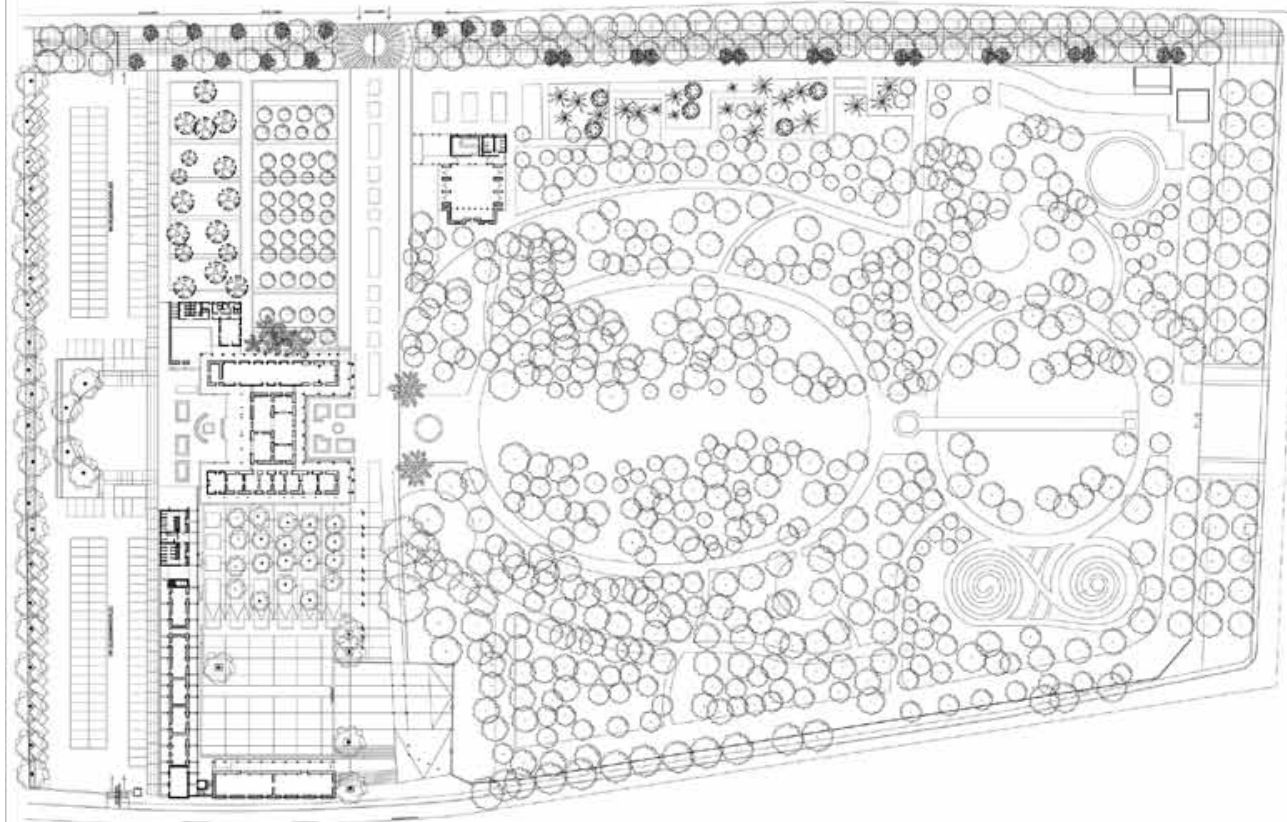

Emplazamiento 

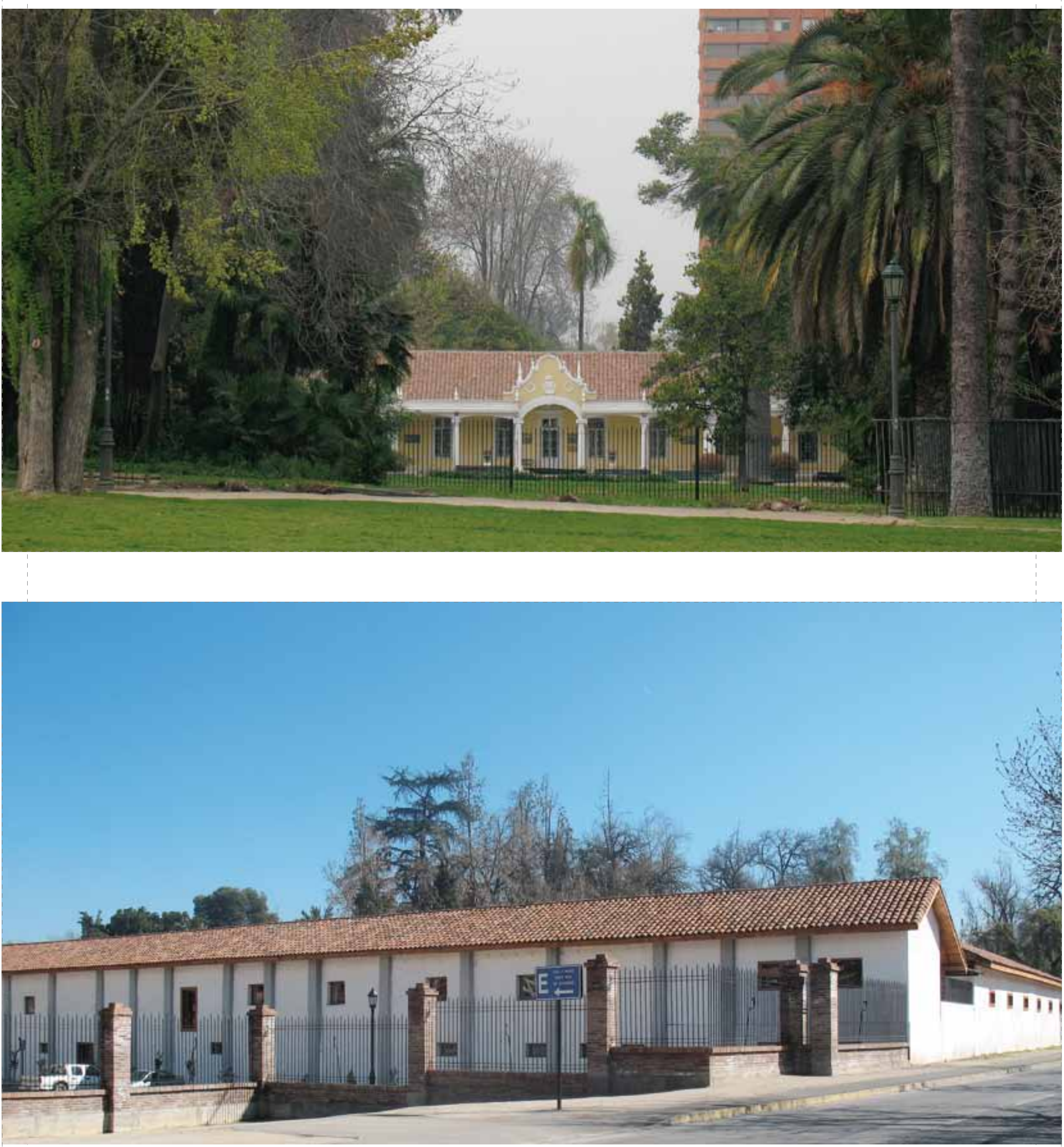


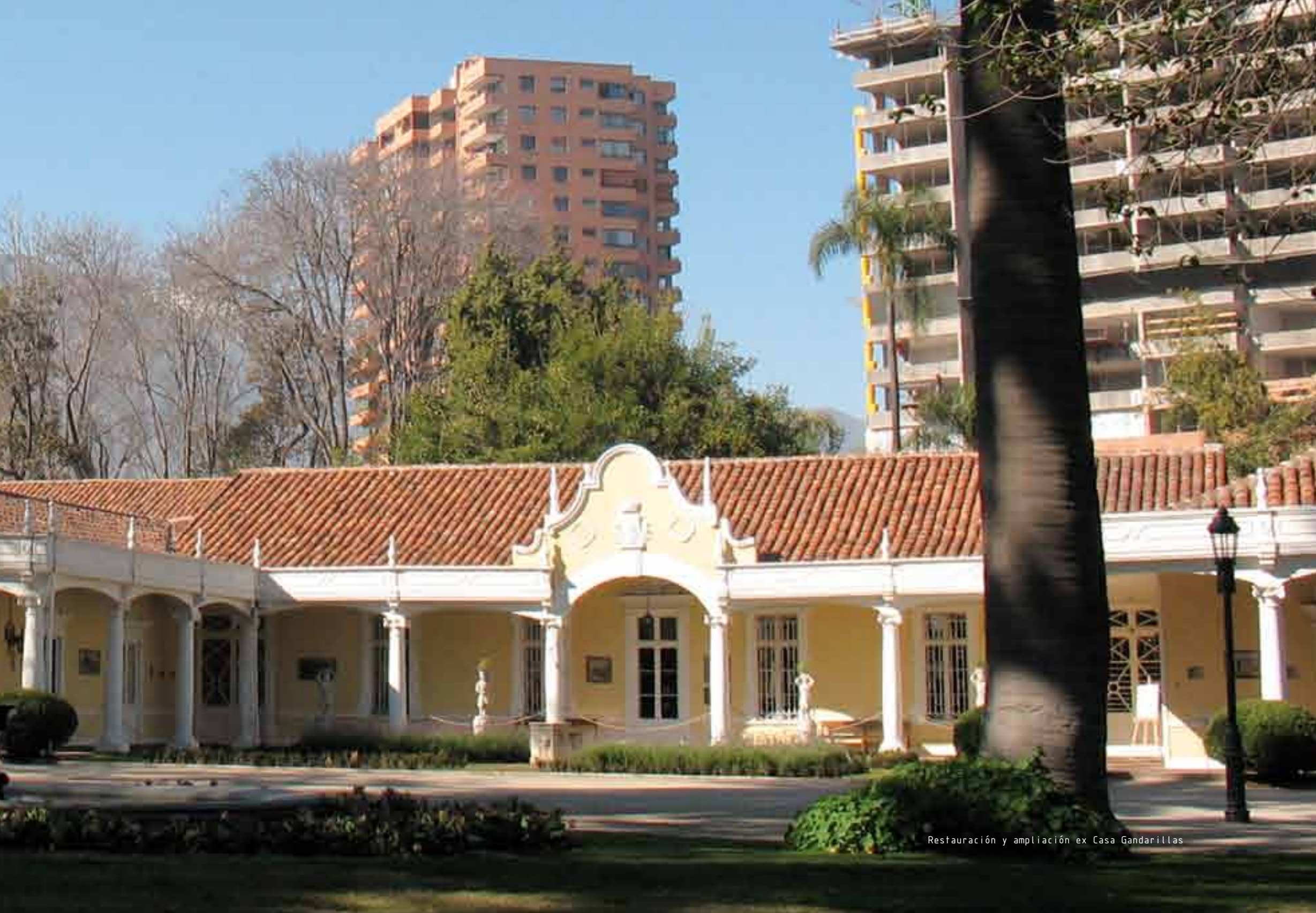




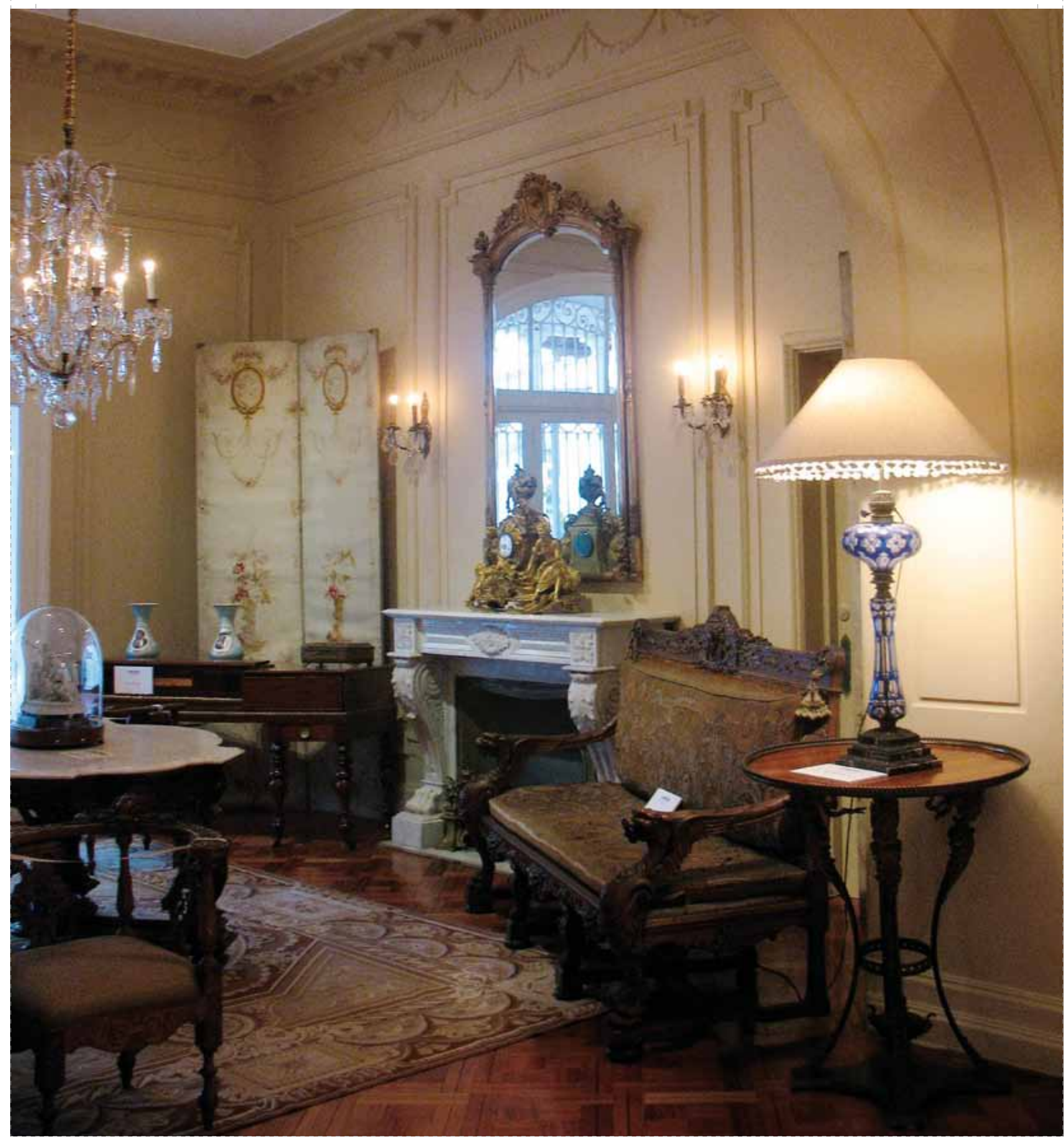




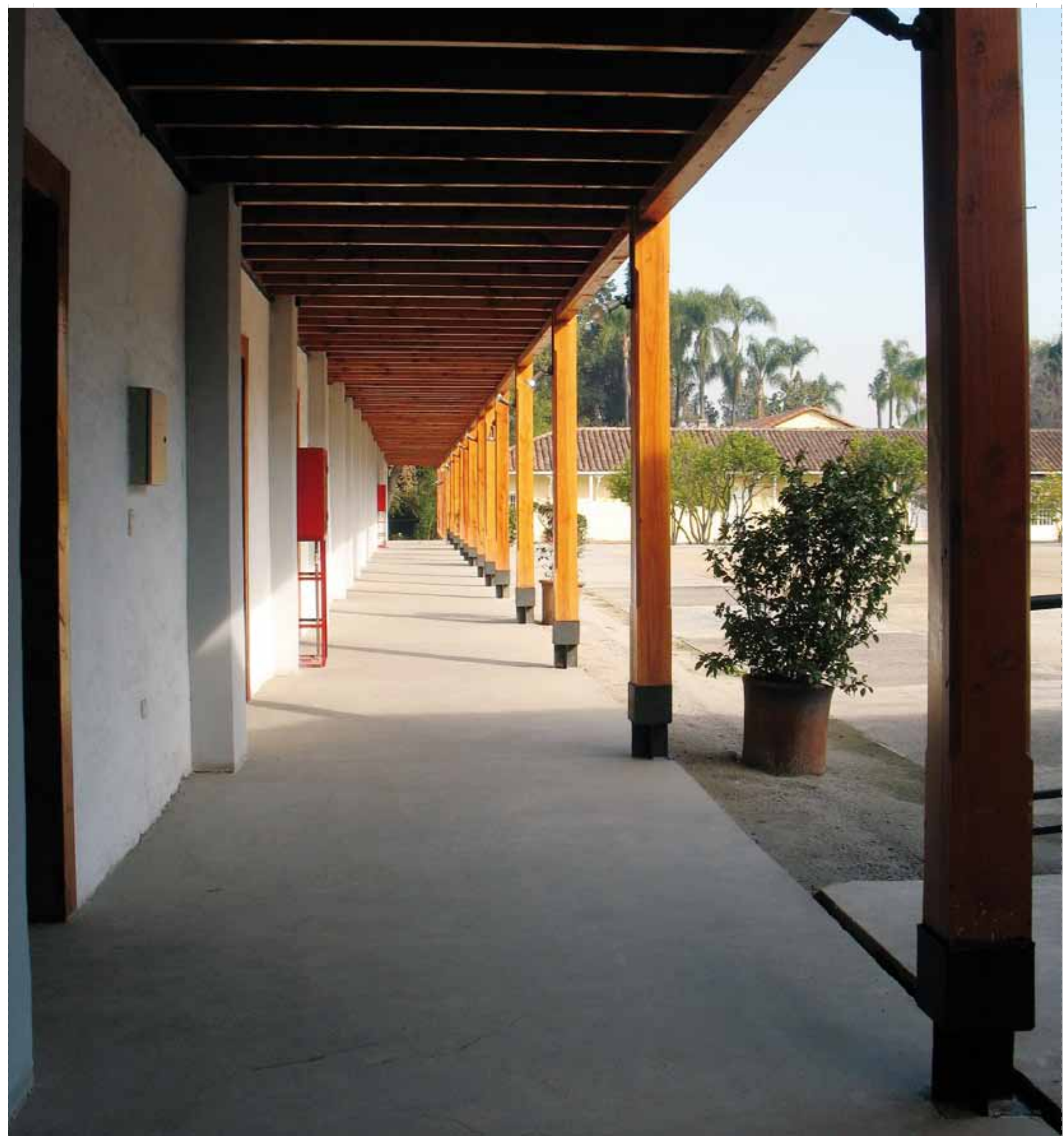




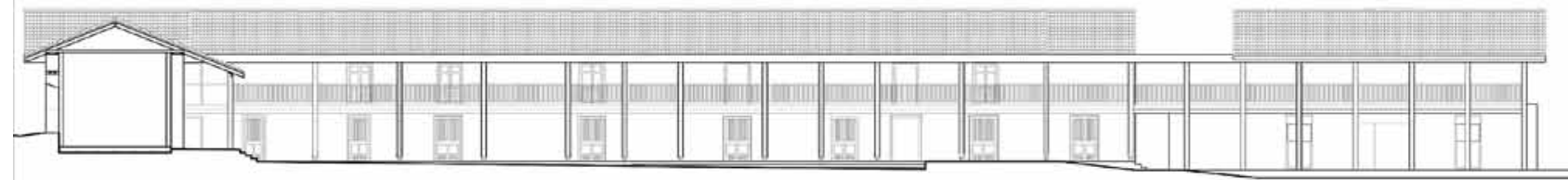

Corte-Elevación Norte

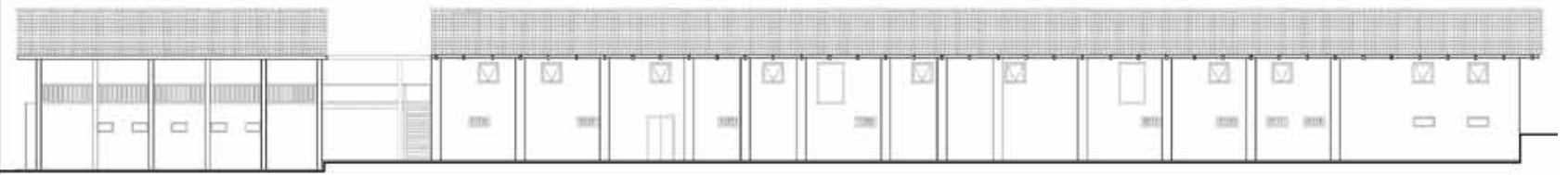

Elevación Sur

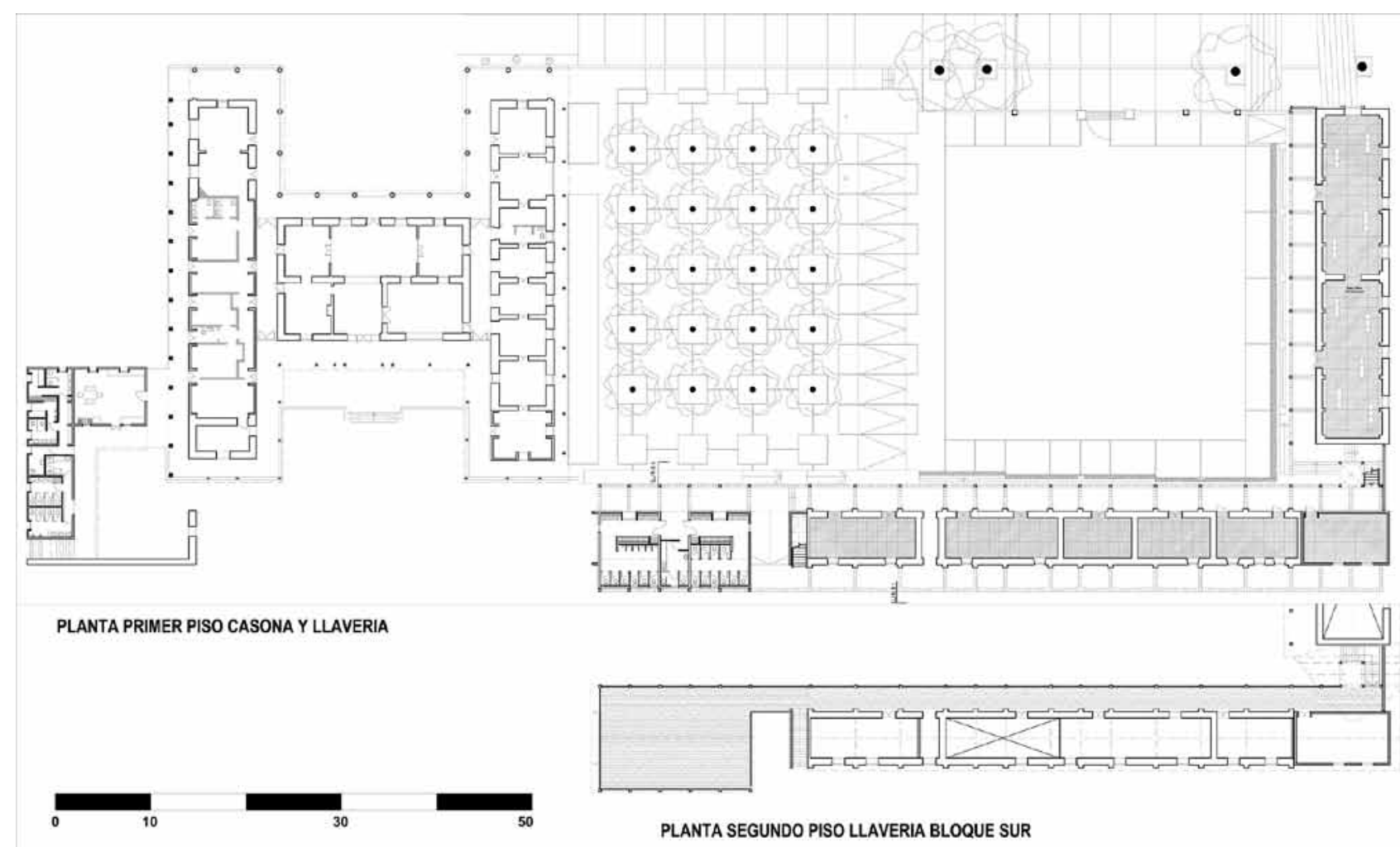




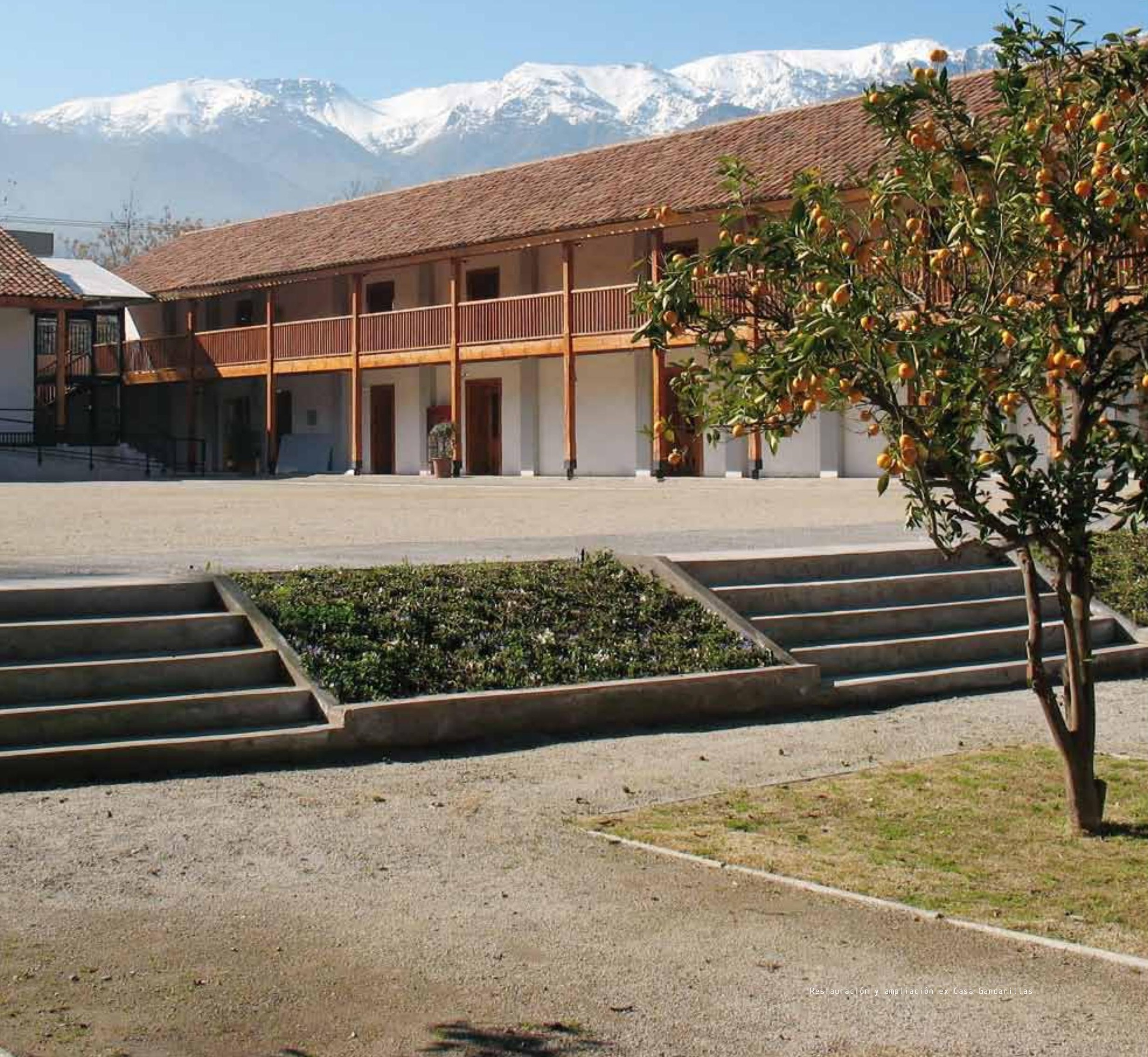

